\title{
LA SEÑAL ARQUEOLÓGICA DEL INTERIOR DEL BOSQUE EN LA MARGEN SUR DEL LAGO SAN MARTÍN (PROVINCIA DE SANTA CRUZ)
}

\section{THE ARCHAEOLOGICAL SIGNAL OF THE FOREST INTERIOR IN THE SOUTH MARGIN OF THE SAN MARTIN LAKE (SANTA CRUZ PROVINCE).}

\author{
Juan Bautista Belardi ${ }^{1}$ y Flavia Carballo Marina ${ }^{2}$
}

\begin{abstract}
1. Universidad Nacional de la Patagonia Austral. CONICET. Campus Universitario, Avda. Gregores y Piloto Lero Rivera s/n. (9400). Río Gallegos, Santa Cruz, Argentina. E-mail: juanbautistabelardi@gmail.com 2. Universidad Nacional de la Patagonia Austral. Campus Universitario, Avda. Gregores y Piloto Lero Rivera s/n. (9400). Río Gallegos, Santa Cruz, Argentina. E-mail: flaviacarballomarina@gmail.com
\end{abstract}

Presentado el: 31/10/2013 - Aceptado 12/06/2014

\begin{abstract}
Resumen
En la cuenca del lago San Martín las mayores densidades artefactuales relacionadas con el uso del borde de bosque de Nothofagus se observan sobre la margen sur del lago y corresponden al istmo de la península Maipú. Nueva evidencia del interior del bosque al oeste del istmo muestra concentraciones líticas de baja densidad y riqueza artefactual. La información paleoambiental indica que estos conjuntos siempre estuvieron en el bosque. Se destaca la relativa continuidad espacial de la señal arqueológica y el empleo mayoritario y expeditivo de rocas disponibles localmente. No obstante, el uso de rocas alóctonas (obsidiana y limolita) sugiere la entrada al bosque desde el Este por individuos equipados. Se sostiene la circulación por caminos de menor costo con tránsito ocasional y por corto tiempo. Ello, y la marcada estacionalidad apoya el uso marginal de este ambiente (sensu Borrero 2004). La articulación con el interior del bosque habría sucedido principalmente durante el Holoceno tardío, cuando las cuencas de los lagos Tar y San Martín estaban efectivamente ocupadas (sensu Borrero 1994-1995). La información obtenida es congruente con la registrada en otras cuencas del sur de Santa Cruz y difiere de la de norpatagonia (provincias de Río Negro y Chubut).
\end{abstract}

Palabras claves: Lago San Martín, Bosque, Uso del espacio, Marginalidad. 


\begin{abstract}
The highest artifactual densities related to hunter-gatherer forest edge use at the San Martin Lake basin were observed in its South shore, on the Maipu Peninsula isthmus. New evidence from the forest interior shows lithic assemblages characterized by low density and richness. Palaeoenvironmental data indicate that these assemblages had always been in the forest. The continuity of the archaeological signal and the main and expeditive use of locally available rocks are worth noting. Nevertheless, artifacts made on aloctonous rocks (obsidian and siltstone) suggest that the coming into the forest was done from the East by equipped individuals. The occasional and short time circulation using low cost paths is sustained. This last evidence and the great seasonality point to the marginal use of the forest (sensu Borrero 2004). The forest-steppe articulation could have occurred principally during the Late Holocene, when the Tar and San Martin Lake basins were already part of the hunter-gatherer landscape (sensu Borrero 1994-1995). The available archaeological information fits the one registered in other basins from southern Santa Cruz Province and differs from North Patagonia (Río Negro and Chubut Provinces) data.
\end{abstract}

Key words: San Martín Lake, Forest, Landscape use, Marginality.

\title{
Introducción
}

Los lagos glaciarios Tar y San Martín se ubican al Suroeste de la provincia Santa Cruz. En la región constituida por estas cuencas, la señal arqueológica indica que las ocupaciones humanas se habrían iniciado hacia 9700 años AP y que la intensidad de uso decrece de EsteOeste (Belardi et al. 2010). Las evidencias más orientales, próximas a la cordillera, ocurren sobre la margen Sur del lago San Martín, en el istmo de la península Maipú, que se vincula con el borde de bosque y se caracteriza por poseer una alta frecuencia artefactual (Espinosa et al. 2009). El Oeste de la región conforma un cul de sac (sensu Aschero 1996) debido a la presencia del Campo de Hielo Patagónico Sur (CHPS), por lo que responde a una marcada estacionalidad y sólo pudo ser utilizado durante la primavera y el verano (Figura 1).

Se presenta nueva evidencia arqueológica acerca del uso del interior del bosque caducifolio de lenga (Nothofagus pumilio) de la margen Sur del lago San Martín hacia el Oeste del istmo de la península Maipú. La información se focaliza sobre conjuntos líticos recuperados en contextos a cielo abierto en estratigrafía y en superficie obtenida en campos de Ea. El Cóndor. El relevamiento fue realizado en la margen Oeste del brazo Maipú del lago San Martín, sobre las cotas 250 y 350 m, entre el casco de la Ea. El Cóndor y el Hito 62 (límite con Chile) (Figura 2). Fue planteado buscando la pendiente menos abrupta y el bosque abierto, elección que resulta en un camino de menor costo debido a que la topografía encauza y dirige la circulación (ver Surface-Evans y White 2012). Se reconocieron diferentes geoformas: terrazas fluviales y lacustres, morrenas y afloramientos rocosos de la Fm. Chon Aike (Andreone 2011).

El uso del bosque en Patagonia Sur, provincia de Santa Cruz, ha sido motivo de diversas evaluaciones (entre otros, Aschero et al. 2005; Belardi et al. 1994; Belardi y Campan 1999; Borrero 1994-1995; Borrero y Muñoz 1999; Espinosa 2000, 2002; Franco et al. 1999; Charlin et al. 2011). La discusión ha girado sobre la forma e intensidad de uso de este ambiente y la manera en que se articuló la movilidad entre la estepa y el bosque a lo largo del tiempo. Aquí se amplía lo conocido acerca de la arqueología de este ambiente y de la región, ya que sólo se disponía de datos del borde del bosque obtenidos en la margen Norte (Espinosa et al. 2013) y en la margen Sur del lago (Espinosa et al. 2009). 
En primer lugar se caracteriza al bosque actual y se consideran las distintas fluctuaciones ambientales acaecidas a lo largo del Holoceno. Luego, se resumen los antecedentes de investigación sobre el uso cazador recolector del bosque en el Sur de la provincia de Santa Cruz. Los resultados alcanzados indican la relativa continuidad espacial de la señal arqueológica, sin embargo el tránsito habría sido ocasional, por corto tiempo y en forma estacional. Lo señalado apoya planteos previos sobre la marginalidad (sensu Borrero 2004) de dichos espacios en los circuitos de movilidad de las poblaciones cazadoras recolectoras que habitaron el lago San Martín (Belardi et al. 2010; Espinosa et al. 2009, 2013). En este sentido, las ocupaciones del bosque no pueden verse como un fenómeno disociado del uso de la estepa sino como un reflejo de la ampliación del rango de acción y exploración por parte de dichas poblaciones. Por último, los resultados son ponderados con los alcanzados en el Sur de Santa Cruz y, en conjunto, con los obtenidos en el Norte de Patagonia (provincias de Río Negro y Chubut).

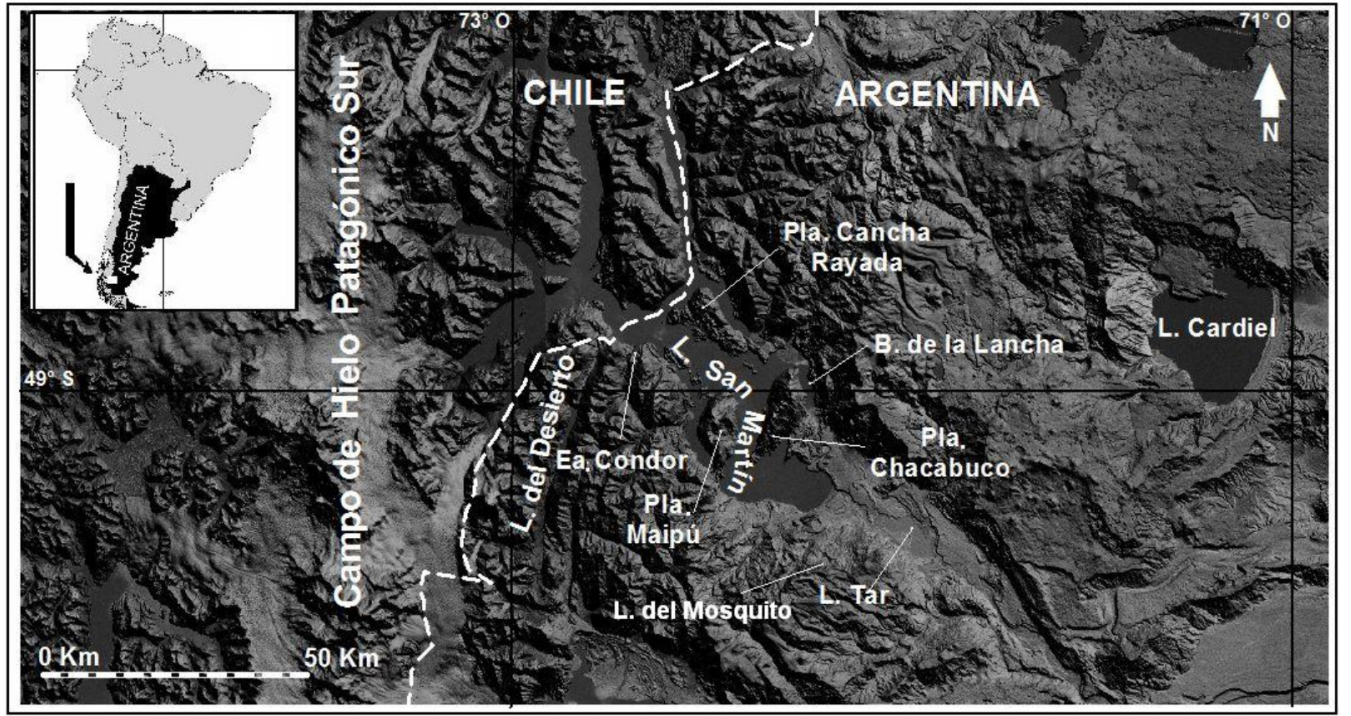

Figura 1. Ubicación de la región de estudio.

\section{El bosque en la cuenca del lago San Martín}

La cuenca del lago San Martín está circunscripta por mesetas altas y la cordillera andina. Se orienta al noroeste-sudeste y se encuentra rodeada por distintos sistemas de morenas (Aüer y Cappannini 1957; Bonarelli y Nágera 1921), razón por la cual en superficie se exponen rocas de variada litología (algunas de ellas aptas para la talla -sensu Aragón y Franco 1997). Hacia el Oeste limita con el CHPS.

En la margen Norte del lago se ubica una de las principales masas forestales de la provincia de Santa Cruz y es de destacar que no se encuentran en retracción. El bosque actual, caracterizado por Nothofagus también se manifiesta en las penínsulas Maipú y Chacabuco (Figura 1). Aquí, este ecosistema se define por una cobertura intermedia con áreas sin árboles mientras que hacia el Norte las pendientes son abruptas y el bosque cerrado (Peri y Ormaechea 2013). En el Sureste se destaca la presencia de una isleta de bosque de Nothofagus de unos 2,4 km². Se ubica entre las cotas $820-980 \mathrm{~m}$ al pie de una amplia cuenca endorreica 
enmarcada por una morena lateral, denominada laguna del Mosquito (Figura 1). El ecotono es estrecho, varía en su extensión aunque no supera los $10 \mathrm{~km}$, y se encuentra relacionado con la geomorfología (Movia et al. 1987).

Entre los 11.300 y 10.000 años cal AP., se desarrolló una estepa sub-arbustiva bajo condiciones muy áridas, hecho que sugiere precipitaciones menores a los $200 \mathrm{~mm}$ anuales. Entre los 10.000 y 8000 años cal AP. la presencia de una estepa graminosa en la zona extra-Andina y el comienzo de la expansión del bosque de Nothofagus indican condiciones más húmedas que las anteriores. Entre los 8000 y 3000 años cal AP., se refleja una menor humedad dado el desarrolló una estepa graminosa con una alta representación de arbustos. A partir del incremento en la señal de Nothofagus se infiere que el bosque continuó expandiéndose. Entre los 3000 y 100 años cal AP., la presencia de la estepa graminosa muestra el retorno de las condiciones de mayor humedad, mientras que la señal de bosque se mantiene relativamente constante. Por otra parte, los altos valores de partículas de carbón indican incendios frecuentes entre 3000 y 2500 años cal. AP (Sottile et al. 2012), situación que habría repercutido directamente en las posibilidades de circulación por el bosque por parte de los cazadores recolectores.

Las características ambientales del último siglo estuvieron determinadas por importantes cambios relacionados con fluctuaciones estacionales y el impacto antrópico (Bamonte y Mancini 2011).

Toda esta información es concordante con la propuesta de una alternancia entre períodos húmedos y secos (Aüer y Cappannini 1957). En igual sentido se orientan los registros del lago Cardiel al indicar una mayor estacionalidad durante el Holoceno medio y tardío (Gilli et al. 2001). Los avances neoglaciales ocurridos entre 8500 y 7500 años A.P. y entre 5800-5500 años A.P. (Wenzens 1999), que se corresponden con los dos momentos de mayor disponibilidad de humedad, habrían dificultado y/o inhibido la circulación por el bosque.

El análisis de los sedimentos del fondo del lago del Desierto - ubicado inmediatamente al Oeste del lago San Martín - muestra que, alrededor de 850 años cal. AD, comienza la Anomalía Climática Medieval (ACM), momento más cálido que el actual que finaliza en torno a los 1450 años cal. AD (Kastner et al. 2010). El ambiente se vuelve más frío y húmedo durante la Pequeña Edad del Hielo, que concluye hacia 1750 años AD (Masiokas et al. 2009).

En resumen, el bosque habría variado en su estructura, composición y densidad del componente arbóreo, situaciones que habrían afectado (favoreciendo o dificultando) la circulación de las poblaciones cazadoras recolectoras. Sobre la base de los datos paleoambientales es posible sostener que toda la evidencia arqueológica que se presenta se encontraba en el interior del bosque. En líneas generales el borde de bosque no presenta recursos diferentes ni en el tipo ni la frecuencia (distintas maderas y el huemul -Hippocamelus bisulcus) respecto de su interior. Una excepción está dada por la presencia en el istmo de la península Maipú de toba silicificada verde (ver abajo), roca de muy buena calidad para la talla (sensu Franco y Aragón 1997).

\section{El uso del bosque en el Sur de Santa Cruz}

El bosque es un ecosistema que ha sido integrado en forma más tardía que la estepa a la discusión del poblamiento de Patagonia (ver Borrero 1994-1995). Se ha planteado que su utilización por los cazadores recolectores se dió exclusivamente en forma estacional y en 
relación con la explotación de un ambiente más productivo como la estepa. En este sentido, su uso es visto como marginal, ya que habría sido discontínuo (Borrero 2004) y realizado por medio de partidas logísticas, característica común a todas las regiones que se mencionan a continuación.

El Parque Nacional Perito Moreno, principalmente en torno a las cuencas de los lagos Belgrano y Burmeister, es la región con mayor intensidad y continuidad de uso sobre el borde de bosque, la que decrece hacia el interior (Aschero et al. 2005; Espinosa 2000 , 2002). La poca información disponible para la cuenca superior del lago Viedma, en cercanías de la localidad de El Chaltén, muestra escaso material en superficie en torno al borde de bosque al igual que hacia el interior -donde hay dos bloques con motivos de guanacos pintados- que sostienen un uso humano poco intenso (Belardi y Caracotche 2005). Esta misma situación se registró en la región lago Argentino (Belardi et al. 1994; Belardi y Campan 1999; Borrero y Muñoz 1999; Franco 2002; Franco et al. 1999, entre otros) a partir de la información proveniente de la margen Este del lago Roca y del Oeste del Brazo Sur -que es el espacio más cercano al CHPS. La cuenca superior del río Gallegos tiene una posición geográfica diferente, ya que sus nacientes se encuentran desconectadas del CHPS, dando como resultado una estacionalidad menos marcada y la factibilidad de circulación entre ambas vertientes oceánicas. Lo señalado habría resultado en un acceso al bosque sumamente sencillo debido a la topografía suave y en la posibilidad de ser ocupado durante un lapso mayor. En este sentido, la evidencia indica que determinados puntos del bosque, como la laguna Cóndor, habrían actuado como nodos ocupacionales (Charlin et al. 2011).

Todos estos resultados se ven reforzados por los provenientes de la vertiente pacífica en la XI Región, Aisén (Chile). Tanto la evidencia artefactual (Méndez y Reyes 2008) como la isotópica -obtenida sobre restos humanos- (Méndez et al. 2013) son concordantes con el uso discontinuo y marginal del bosque (ver también Borrero 2004).

\section{El caso de la cuenca del lago San Martín}

La principal evidencia arqueológica relacionada con el uso del bosque por parte de las poblaciones cazadoras recolectoras proviene de la margen Sur del lago San Martín. Se determinó que el istmo de la península Maipú es el espacio que se destaca por su equipamiento puesto de manifiesto por la alta frecuencia de molinos registrados en cuencas de deflación, así como por la presencia de artefactos manufacturados sobre toba silicificada verde. Además, se recuperaron artefactos confeccionados en rocas alóctonas como la obsidiana y la limolita. La primera de ellas proviene de la Pampa del Asador (Espinosa y Goñi 1999) (distante unos 200 km al NE). Por su parte, la limolita se encuentra sobre la margen Oeste del lago Cardiel (distante unos $100 \mathrm{~km}$ hacia el Noreste) (Belardi et al. 2013). Las rocas silíceas estarían disponibles localmente (principalmente en las mesetas circundantes a las cuencas de los lagos Tar y San Martín) y/o proceder del Macizo del Deseado. Se ha constatado su presencia bajo la forma de artefactos al sur del Macizo, situación que se explicaría por el trasporte o la circulación de las poblaciones humanas (Franco et al. 2011). El descarte de artefactos de materias primas alóctonas llevó a proponer una estrategia de equipamiento de individuos que acceden a estos espacios desde el Este, y desde donde se articularon actividades logísticas al interior del bosque sobre una base estacional. Las variaciones observadas en las frecuencias/ densidades artefactuales son importantes porque indican que el uso y la circulación 
humana estuvieron concentrados en el istmo y no hacia el interior de la península Maipú. Dado que no existen diferencias en cuanto a la disponibilidad de recursos básicos como el guanaco (Lama guanicoe), agua y espacios protegidos, se sugiere que el istmo debió ser el lugar occidental de más fácil acceso desde el Este (Espinosa et al. 2009). Asimismo, se vuelve un paso obligado para la circulación hacia el Oeste. También se relevó el lado Este del interior de la península, sin que se produjeran hallazgos. Por su parte, en el Oeste la pendiente es muy abrupta y cae hacia el lago por lo que no fue recorrida. El registro arqueológico del istmo de la península Maipú sería el resultado de una circulación pautada, donde la disponibilidad de toba silicificada verde fue uno de los escasos recursos exclusivos de este ambiente (Espinosa et al. 2009).

Sobre la margen Norte del lago San Martín también se realizaron hallazgos en el ecotono bosque-estepa y próximos al borde de bosque. Aquí no existe un recurso exclusivo como la toba silicificada verde. La evidencia proviene de lagunas ubicadas en la península Chacabuco y en Bahía la Lancha, así como de abrigos rocosos (cueva y alero del Paisano Desconocido) localizados sobre el extremo Noreste de la bahía y muy escasos artefactos aislados encontrados en el istmo de la península Cancha Rayada (Figura 1). La cronología obtenida en las ocupaciones bajo roca ronda los 8000 años AP. No obstante, el patrón resultante es semejante a lo hasta ahora conocido para la margen Sur: baja densidad artefactual en superficie, el empleo de los mismos tipos de rocas para la manufactura de artefactos y bajas tasas de depositación en los momentos iniciales de ocupación y su aumento hacia el Holoceno tardío final. Una vez más se manifiesta la baja intensidad de uso de estos espacios y la implementación de partidas logísticas desde el Este (Espinosa et al. 2013).

En definitiva, el uso del bosque del lago San Martín es considerado marginal en términos de su baja intensidad y discontinuidad. Su incorporación plena a los circuitos de movilidad cazadores recolectores habría ocurrido cuando las cuencas de los lagos Tar y San Martín estaban siendo efectivamente ocupadas (sensu Borrero 1994-1995). La información que se presenta a continuación permite evaluar y ajustar esta propuesta.

\section{La nueva evidencia del interior del bosque en la margen Sur del lago San Martín}

Los relevamientos se concentraron hacia el Oeste del istmo de la península Maipú, en torno a la desembocadura de los ríos Grande, Gallo, Mackenna y Martínez Rosas (límite con Chile) (Figura 2). Se privilegió el registro de los sectores de bosque abierto y se focalizó sobre las denominadas "ventanas de visibilidad" -espacios con mayor visibilidad arqueológica-, tales como cuencas de deflación o cicatrices de erosión en morenas y terrazas lacustres y fluviales, huellas vinculadas con la extracción de leña, árboles caídos y sendas de caballo. Las dimensiones de las superficies erosionadas son muy variables y se consideraron a partir del eje mayor orientado en sentido E-O y N-S. Se llevaron a cabo transectas lineales con muestreos de $100 \mathrm{~m} \times 10 \mathrm{~m}$. Por otra parte, se efectuó un sondeo estratigráfico en el único reparo rocoso en el que se observó material arqueológico en superficie.

Al enumerar la nueva evidencia se toma como punto de inicio el Oeste del brazo Maipú del lago San Martín (Tabla 1 y Figura 2). En la Tabla 1 se discriminan los hallazgos efectuados por geoforma, la superficie y la frecuencia artefactual relevados. Además, se prospectó un total de $22.000 \mathrm{~m}^{2}$ en otros espacios de muy buena visibilidad arqueológica donde no se 
produjeron hallazgos. Para evaluar la diversidad artefactual se consideraron sólo aquellos artefactos que presentaban talón, núcleos y artefactos formatizados. En estos últimos, no se detectaron casos de remontaje (Tablas 2 a 11). Los tipos artefactuales (desechos y artefactos formatizados) se los adscribe tecnotipológicamente siguiendo los lineamientos propuestos por Aschero (1975/1983) .

El análisis también contempla la descripción de la distribución de tamaños, para lo que se separa entre artefactos enteros y fracturados y para el caso de los desechos, el tipo de talón. Toda esta información se presenta agregada para cada uno de los sectores analizados (Tablas 12 a 14). Además, en los núcleos $(n=2)$ se consideró el porcentaje de reserva de corteza y el número mínimo de extracciones.

Las materias primas líticas se diferencian macroscópicamente a partir del reconocimiento de nódulos y el agrupamiento de los artefactos por nódulo (sensu Larson y Kornfeld 1997). Por último, se determinó su calidad para la talla siguiendo la propuesta de Aragón y Franco (1997). En este sentido, la obsidiana es considerada excelente, mientras que las sílices, las calcedonias, la toba silicificada verde, las maderas silicificadas, las dacitas, los basaltos y la limolita son de muy buena calidad. Por último, la lutita, la toba, la cuarcita y la riolita son de buena calidad. El 81\% de los artefactos recuperados en el interior del bosque están enteros, tanto para los desechos de talla como para los artefactos formatizados. Si bien se trata de una muestra pequeña (Tabla 1), lo señalado indica la alta integridad de la misma.

\begin{tabular}{|l|l|l|l|}
\hline Geoforma / denominación & $\begin{array}{l}\text { Superficie } \\
\text { Relevada } \\
\left(\mathrm{m}^{2}\right)\end{array}$ & $\begin{array}{l}\text { N desechos } \\
\text { con talón y } \\
\text { artefactos } \\
\text { formatizados }\end{array}$ & $\begin{array}{l}\text { N desechos sin } \\
\text { talón }\end{array}$ \\
\hline $\begin{array}{l}\text { 1. III Terraza del río Cóndor. Ruta Provincial } \\
\text { No } 41 .\end{array}$ & 4000 & 3 & 0 \\
\hline 2. III Terraza del río Cóndor. Bloque El Cóndor. & 1 & 142 & 45 \\
\hline 3. Valle del río Cóndor. Bosque lenero & 4000 & 0 & 0 \\
\hline 4. Terraza del río Grande. Cuenca de deflación II. & 118 & 13 & 6 \\
\hline 4. Terraza del río Grande. Cuenca de deflación III. & 460 & 7 & 0 \\
\hline 4. Terraza del río Grande. Cuenca de deflación IV. & 603 & 15 & 2 \\
\hline 5. Terraza del río Gallo. Cuenca de deflación III. & 105 & 4 & 0 \\
\hline $\begin{array}{l}\text { 6. Morena al Este del istmo de la Pla. Mackenna. } \\
\text { Cuenca de deflación superior. }\end{array}$ & 1500 & 18 & 1 \\
\hline $\begin{array}{l}\text { 6. Morena al Este del istmo de la Pla. Mackenna. Cuenca } \\
\text { de deflación inferior I. }\end{array}$ & 1000 & 10 & 0 \\
\hline $\begin{array}{l}\text { 6. Morena al Este del istmo de la Pla. Mackenna. Cuenca } \\
\text { de deflación inferior II. }\end{array}$ & 500 & 6 & 0 \\
\hline $\begin{array}{l}\text { 7. Terraza lacustre. Puesto Martínez Rosas I. } \\
\text { Cuenca de deflación debajo del puesto. }\end{array}$ & 1024 & 22 & 3 \\
\hline $\begin{array}{l}\text { 7. Terraza lacustre. Puesto Martínez Rosas II. } \\
\text { Cuenca de deflación frente al puesto. }\end{array}$ & 192 & 29 & 5 \\
\hline \multicolumn{1}{|c|}{ TOTALES } & 13.503 & 239 & 68 \\
\hline
\end{tabular}

Tabla 1. Geoformas, lugares relevados y frecuencias artefactuales. Referencias: los números arábigos de la columna Geoforma / denominación remiten a la Figura 2. 


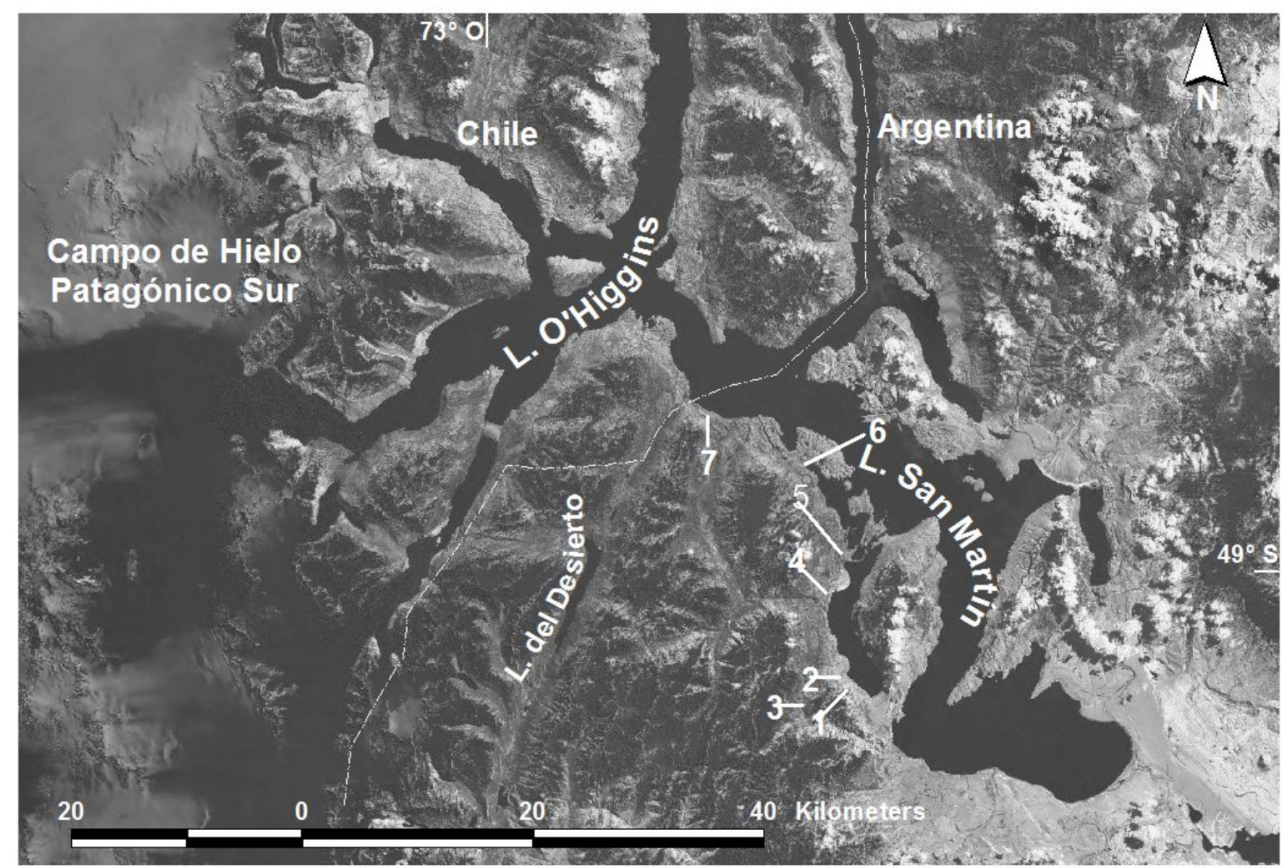

Figura 2. Ubicación de las geoformas y de los lugares relevados.

\section{Terraza del río Cóndor}

En proximidad del casco de la estancia El Cóndor, sobre la III terraza ubicada en la margen derecha del río Cóndor (335 msnm) y sobre una huella interna, se registró una hemibola de gabro con surco ecuatorial (largo $66,5 \mathrm{~mm}$, ancho $55,5 \mathrm{~mm}$ y $45 \mathrm{~mm}$ de espesor), una lasca plana de toba silicificada verde y una lasca de arista de basalto. Las dimensiones y talones de estos dos últimos artefactos son considerados, dada su cercanía, junto con los del bloque El Cóndor (Tablas 12 a14).

\section{Terraza del río Cóndor. Bloque El Cóndor}

Se relevó un bloque rocoso de riolita -producto del deslizamiento gravitacional- correspondiente a la Fm. Chon Aike. Tiene unos $12 \mathrm{~m}$ de largo por $8 \mathrm{~m}$ de ancho, 1,50 $\mathrm{m}$ de reparo y unos $5 \mathrm{~m}$ de altura (Figura 3), su frente se orienta al NE. Se detectaron artefactos líticos en superficie, por lo cual se realizó una excavación de $1 \mathrm{~m}^{2}$ en la parte central del bloque y contra la pared de roca. Se emplearon niveles artificiales de cinco $\mathrm{cm}$ hasta alcanzar el nivel estéril a $0,75 \mathrm{~cm}$ (nivel $0=35 \mathrm{~cm}$ ). El sedimento es francoarenoso a arenosofranco y pese a presentar un ph 8 no se registraron restos óseos que permitieran su datación. Sólo se recuperaron artefactos líticos (Tablas 1 y 2).

Los artefactos se distribuyen estratigráficamente de la siguiente manera: el nivel inicial $(70-75 \mathrm{~cm})$ tiene nueve y el siguiente $(65-70 \mathrm{~cm})$ es el de mayor frecuencia con 80 artefactos. En los niveles restantes la frecuencia artefactual decae abruptamente, ya que en el nivel $60-65 \mathrm{~cm}$ se registran 21 artefactos y los otros materiales $(n=32)$ se distribuyen de manera homogénea entre el nivel de $60 \mathrm{~cm}$ y la superficie. En el nivel con mayor frecuencia arte- 


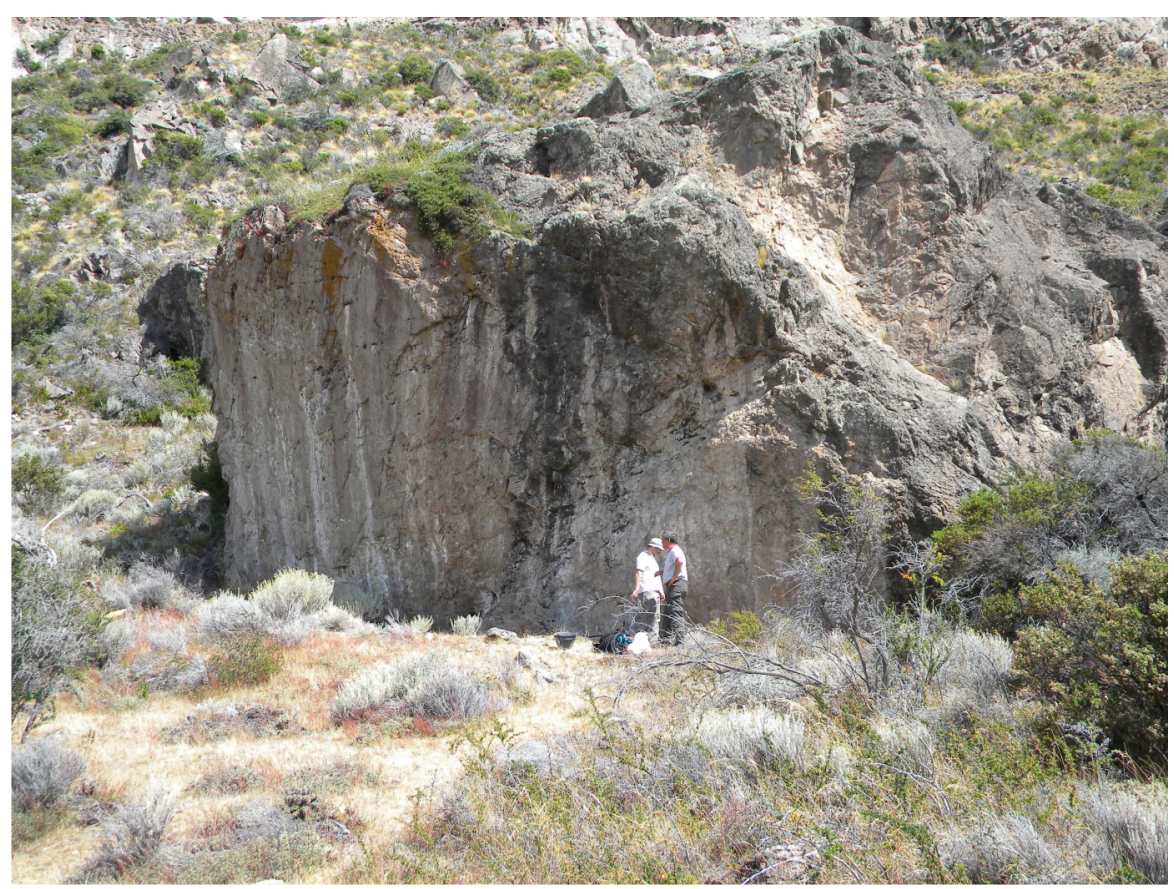

Figura 3. Bloque El Cóndor.

\begin{tabular}{|l|l|l|l|l|l|l|l|l|l|}
\hline Tipo Artefactual & Sílice & Dacita & Toba & TSV & Basalto & M. sil. & Obsidiana & Calcedonia & $\begin{array}{l}\text { Total y } \\
\%\end{array}$ \\
\hline L. primaria & 0 & 0 & 1 & 0 & 0 & 0 & 0 & 0 & $1 / 0,70$ \\
\hline L. secundaria & 0 & 0 & 0 & 0 & 0 & 1 & 0 & 0 & $1 / 0,70$ \\
\hline L. angular & 33 & 32 & 23 & 21 & 3 & 2 & 2 & 2 & $118 / 83$ \\
\hline L. plana & 0 & 2 & 1 & 1 & 0 & 0 & 0 & 0 & $4 / 2,81$ \\
\hline L. arista & 0 & 0 & 0 & 0 & 1 & 0 & 0 & 0 & $1 / 0,70$ \\
\hline L. r. bif. & 4 & 1 & 3 & 0 & 0 & 0 & 1 & 0 & $9 / 6,33$ \\
\hline Núcleo & 1 & 0 & 0 & 0 & 0 & 0 & 0 & 0 & $1 / 0,70$ \\
\hline Raedera & 0 & 0 & 0 & 3 & 0 & 1 & 1 & 0 & $5 / 3,52$ \\
\hline FAF & 0 & 1 & 0 & 0 & 1 & 0 & 0 & 0 & $2 / 1,40$ \\
\hline Total y \% & $38 /$ & $36 /$ & $28 /$ & $25 /$ & $5 /$ & $4 /$ & $4 /$ & $2 /$ & 142 \\
& 26,76 & 25,35 & 19,71 & 17,6 & 3,52 & 2,81 & 2,81 & 1,40 & \\
\hline
\end{tabular}

Tabla 2. Bloque El Cóndor. Frecuencias de tipos artefactuales por materia prima. Referencias: L.: lasca; L. r. bif.L lasca de reducción bifacial FAF: fragmento de artefacto formatizado; TSV: toba silicificada verde; M. sil.: madera silicificada.

factual $(65-70 \mathrm{~cm})$ se destaca la presencia de 15 desechos y tres raederas manufacturadas sobre lascas angulares de toba silicificada verde (dos de filo simple y la restante de filo doble convergente).

En el bloque se habrían continuado las tareas de talla -iniciadas en otro espacio-, dado que se registró un solo núcleo de sílice, agotado y en superficie, y sólo dos desechos con reserva de corteza en toba y madera silicificada. A la vez, hay evidencias de instancias finales de reducción por la presencia de nueve lascas de reducción bifacial $(6,33 \%)$ en cuatro rocas diferentes. Siete de estas lascas se concentran en el nivel $65-70 \mathrm{~cm}$. 
Lo señalado, sumado a la ausencia de material arqueofaunístico que, dado el ph del sedimento no sería explicable por una preservación diferencial, se vincularía con el uso efímero del reparo. Además, su ocupación habría sido más intensa en los momentos iniciales $\mathrm{y}$ vinculados con el uso de la toba silicificada verde.

\section{Valle del río Cóndor. Bosque leñero}

Se recorrió un sector de bosque cerrado de Nothofagus ubicado detrás del casco de la Ea. El Cóndor (Figura 2). Se accedió al mismo por medio de una huella interna utilizada por parte de los propietarios del campo para la extracción de leña, lo que brinda una franja de mayor visibilidad arqueológica. No se produjeron hallazgos.

\section{Terraza del río Grande}

En una terraza de la margen Sur del curso inferior del río Grande, que cae en forma abrupta al brazo Maipú, se localizaron cuatro cuencas de deflación contiguas, formadas sobre morenas en las que se ha depositado sedimento eólico (Andreone 2011). Tres de ellas tienen materiales arqueológicos (Tablas 1 y 3 a 5). Se trata de concentraciones con muy baja frecuencia artefactual y donde las materias primas empleadas son mayoritariamente locales. Se observa en desechos de diversos tipos el empleo de nódulos de lutita (entre el 84 y el $40 \%$ ), disponibles en las cuencas de deflación. Como se ve en la cuenca de deflación II (Tabla 3), las lascas corticales de esta roca superan el $50 \%$. El resto de las materias primas son los sílices $(28,57 \%)$ y el basalto y la toba con un $20 \%$. Se destaca la calcedonia usada para la confección de un biface que se encuentra en estadio 2 (Nami 1986) y un raspador. Para la manufactura de esta última clase artefactual también se emplea la dacita y cabe señalar que todos los raspadores muestran potencial de reactivación. La única raedera fue manufacturada en basalto, está fracturada y tiene potencial de reactivación. El 81,81\% de los conjuntos posee una lasca por nódulo de materia prima, hecho que se relacionaría con la baja producción de desechos de talla y/o el trasporte de éstos a otros sectores.

\begin{tabular}{|l|l|l|l|l|}
\hline Tipo Artefactual & Lutita & Toba & Dacita & Total v \% \\
\hline L. primaria & 3 & 0 & 0 & $3 / 23,07$ \\
\hline L. secundaria & 3 & 0 & 0 & $3 / 23,07$ \\
\hline L. dorso natural & 1 & 0 & 0 & $1 / 7.69$ \\
\hline L. angular & 4 & 0 & 0 & $4 / 30,74$ \\
\hline L. arista & 0 & 1 & 0 & $1 / 7,69$ \\
\hline Raspador & 0 & 0 & 1 & $1 / 7,69$ \\
\hline Total v \% & $11 / 84,61$ & $1 / 7,69$ & $1 / 7,69$ & 13 \\
\hline
\end{tabular}

Tabla 3. Río Grande. Cuenca de deflación II. Frecuencias de tipos artefactuales por materia prima. Referencias. L.: lasca.

\begin{tabular}{|l|l|l|l|l|l|}
\hline Tipo Artefactual & Toba & Sílice & Calcedonia & Basalto & Total v \% \\
\hline L. secundaria & 2 & 0 & 0 & 0 & $2 / 28,57$ \\
\hline L. angular & 1 & 2 & 0 & 0 & $3 / 42,85$ \\
\hline Raspador & 0 & 0 & 1 & 0 & $1 / 14,28$ \\
\hline Raedera & 0 & 0 & 0 & 1 & $1 / 14,28$ \\
\hline Total v \% & $3 / 42,85$ & $2 / 28,57$ & $1 / 14,28$ & $1 / 14,28$ & 7 \\
\hline
\end{tabular}

Tabla 4. Río Grande. Cuenca de deflación III. Frecuencias de tipos artefactuales por materia prima. Referencias. L.: lasca. 


\begin{tabular}{|l|l|l|l|l|l|l|l}
\hline Tipo Artefactual & Lutita & Basalto & Dacita & Sílice & Toba & Calcedonia & Total v $\%$ \\
\hline L. primaria & 1 & 0 & 0 & 0 & 1 & 0 & $2 / 13,33$ \\
\hline L. secundaria & 1 & 0 & 0 & 0 & 0 & 0 & $1 / 6,66$ \\
\hline L. dorso natural & 1 & 0 & 0 & 0 & 0 & 0 & $1 / 6,66$ \\
\hline L. angular & 3 & 2 & 1 & 1 & 0 & 0 & $7 / 46,66$ \\
\hline L. arista & 0 & 1 & 0 & 0 & 0 & 0 & $1 / 6,66$ \\
\hline L. plana & 0 & 0 & 0 & 0 & 2 & 0 & $2 / 13,33$ \\
\hline Biface & 0 & 0 & 0 & 0 & 0 & 1 & $1 / 6,66$ \\
\hline Total v $\%$ & $6 / 40$ & $3 / 20$ & $1 / 6,66$ & $1 / 6,66$ & $3 / 20$ & $1 / 6,66$ & 15 \\
\hline
\end{tabular}

Tabla 5. Río Grande. Cuenca de deflación IV. Frecuencias de tipos artefactuales por materia prima. Referencias. L.: lasca.

Terraza del río Gallo

Se registró una concentración de cuatro desechos de talla en una cuenca de deflación ubicada sobre una terraza de la margen Sur de la desembocadura del río Gallo. Dos son de toba silicificada verde (Tabla 6).

\begin{tabular}{|l|l|l|l|l|}
\hline Tipo Artefactual & TSV & Toba & Basalto & Total y $\%$ \\
\hline L. angular & 2 & 1 & 1 & 4 \\
\hline Total y $\%$ & 2 & 1 & 1 & 4 \\
\hline
\end{tabular}

Tabla 6. Río Gallo. Cuenca de deflación III. Frecuencias de tipos artefactuales por materia prima. Referencias: L.: lasca; TSV: toba silicificada verde.

Morena al Este del istmo de la península Mackenna

Sobre la morena de la margen Este del río Mackenna que desemboca sobre la península homónima se reconocieron tres amplias cuencas de deflación. En ellas se realizó una transecta de tres muestreos (Tablas 1 y 7 a 9), sólo en dos se produjeron hallazgos.

\begin{tabular}{|l|l|l|l|l|l|}
\hline Tipo Artefactual & Toba & Basalto & Cuarcita & Obsidiana & Total y $\%$ \\
\hline L. primaria & 1 & 1 & 0 & 0 & $2 / 11,11$ \\
\hline L. dorso natural & 2 & 0 & 0 & 0 & $2 / 11,11$ \\
\hline L. angular & 7 & 1 & 1 & 1 & $10 / 55,55$ \\
\hline L. indiferenciada & 1 & 0 & 0 & 0 & $1 / 5,5$ \\
\hline Cortante & 0 & 2 & 0 & 0 & $2 / 11,11$ \\
\hline Cepillo & 0 & 1 & 0 & 0 & $1 / 5,5$ \\
\hline Total y $\%$ & $11 / 61,11$ & $5 / 27,77$ & $1 / 5,5$ & $1 / 5,5$ & 18 \\
\hline
\end{tabular}

Tabla 7. Morena sobre la margen Este del río Mackenna. Transecta en cuenca de deflación superior. Frecuencias de tipos artefactuales por materia prima. Referencias: L.: lasca.

\begin{tabular}{|l|l|l|l|l|}
\hline Tipo Artefactual & Toba & M. sil. & Obsidiana & Total v $\%$ \\
\hline L. angular & 1 & 1 & 1 & $3 / 30$ \\
\hline Raedera & 6 & 0 & 0 & $6 / 60$ \\
\hline FAF & 1 & 0 & 0 & $1 / 10$ \\
\hline Total v \% & $8 / 80$ & $1 / 10$ & $1 / 10$ & 10 \\
\hline
\end{tabular}

Tabla 8. Morena sobre la margen Este del río Mackenna. Transecta en cuenca de deflación inferior I. Frecuencias de tipos artefactuales por materia prima. Todo el material fue recuperado en el muestreo 1. Referencias: L.: lasca; FAF: fragmento de artefacto formalizado; M. sil.: madera silicificada. 


\begin{tabular}{|l|l|l|l|l|}
\hline Tipo Artefactual & Toba & Basalto & Riolita & Total y $\%$ \\
\hline L. primaria & 0 & 1 & 0 & $1 / 16,66$ \\
\hline L. angular & 2 & 0 & 0 & $2 / 33,33$ \\
\hline Cepillo & 0 & 0 & 1 & $1 / 16,66$ \\
\hline Raspador & 1 & 1 & 0 & $2 / 33,33$ \\
\hline Total y \% & $3 / 50$ & $2 / 33,33$ & $1 / 16,66$ & 6 \\
\hline
\end{tabular}

Tabla 9. Morena sobre la margen Este del río Mackenna. Transecta en cuenca de deflación inferior II. Frecuencias de tipos artefactuales por materia prima. Todo el material fue recuperado en el muestreo 2. Referencias: L.: lasca.

Los conjuntos están conformados por una baja frecuencia artefactual. No obstante, exponen la mayor riqueza de artefactos formatizados, representada por cinco clases. Algunas de ellas se relacionarían con el trabajo de la madera, como es el caso de los cepillos $(\mathrm{n}=2)$. En las tres cuencas de deflación se recuperaron materias primas locales a excepción de la obsidiana evidenciada por dos lascas angulares (5,5\%). Entre las primeras sobresale la toba cuya representación porcentual ronda entre el 80 y el 60\%. Le siguen en igual orden de importancia el basalto, la cuarcita y la madera silicificada, representados por un único nódulo. Se contabilizó un total de 11 nódulos de toba. En la cuenca de deflación inferior I los materiales se distribuyen en una superficie de $1,5 \mathrm{~m}^{2}$, cinco de las raederas (tres de filo simple y dos de filo doble convergente) y el FAF pudieron ser manufacturadas con el mismo nódulo de toba y ninguno presenta potencial de reactivación. Esta concentración sugiere un evento de talla.

\section{Terraza lacustre. Puesto Martínez Rosas}

Este espacio es el más occidental de todos los relevados en el lago San Martín, se observaron dos cuencas de deflación ubicadas sobre la terraza lacustre más joven. De las concentraciones registradas es la de más alta frecuencia artefactual (Tablas 1, 10 y 11). La primera se localiza por debajo del emplazamiento del Puesto Martínez Rosas y la segunda se encuentra hacia el Sur, cruzando un pequeño cañadón (Figura 4).

\begin{tabular}{|l|l|l|l|l|l|}
\hline Tipo Artefactual & Toba & Sílice & M. sil. & Basalto & Total y \% \\
\hline L. primaria & 1 & 0 & 0 & 1 & $2 / 9,09$ \\
\hline L. secundaria & 1 & 0 & 0 & 0 & $1 / 4,54$ \\
\hline L. dorso natural & 1 & 0 & 0 & 0 & $1 / 4,54$ \\
\hline L. angular & 12 & 0 & 0 & 0 & $12 / 54,54$ \\
\hline L. arista & 1 & 0 & 0 & 0 & $1 / 4,54$ \\
\hline Núcleo & 0 & 0 & 1 & 0 & $1 / 4,54$ \\
\hline Raspador & 0 & 3 & 1 & 0 & $4 / 18,18$ \\
\hline Total y $\%$ & $16 / 72,72$ & $3 / 13,63$ & $2 / 9,09$ & $1 / 4,54$ & 22 \\
\hline
\end{tabular}

Tabla 10. Terraza lacustre. Puesto Martínez Rosas I. (cuenca de deflación debajo del puesto). Frecuencias de tipos artefactuales por materia prima. Referencias: L.: lasca; M. sil.: madera silicificada. 


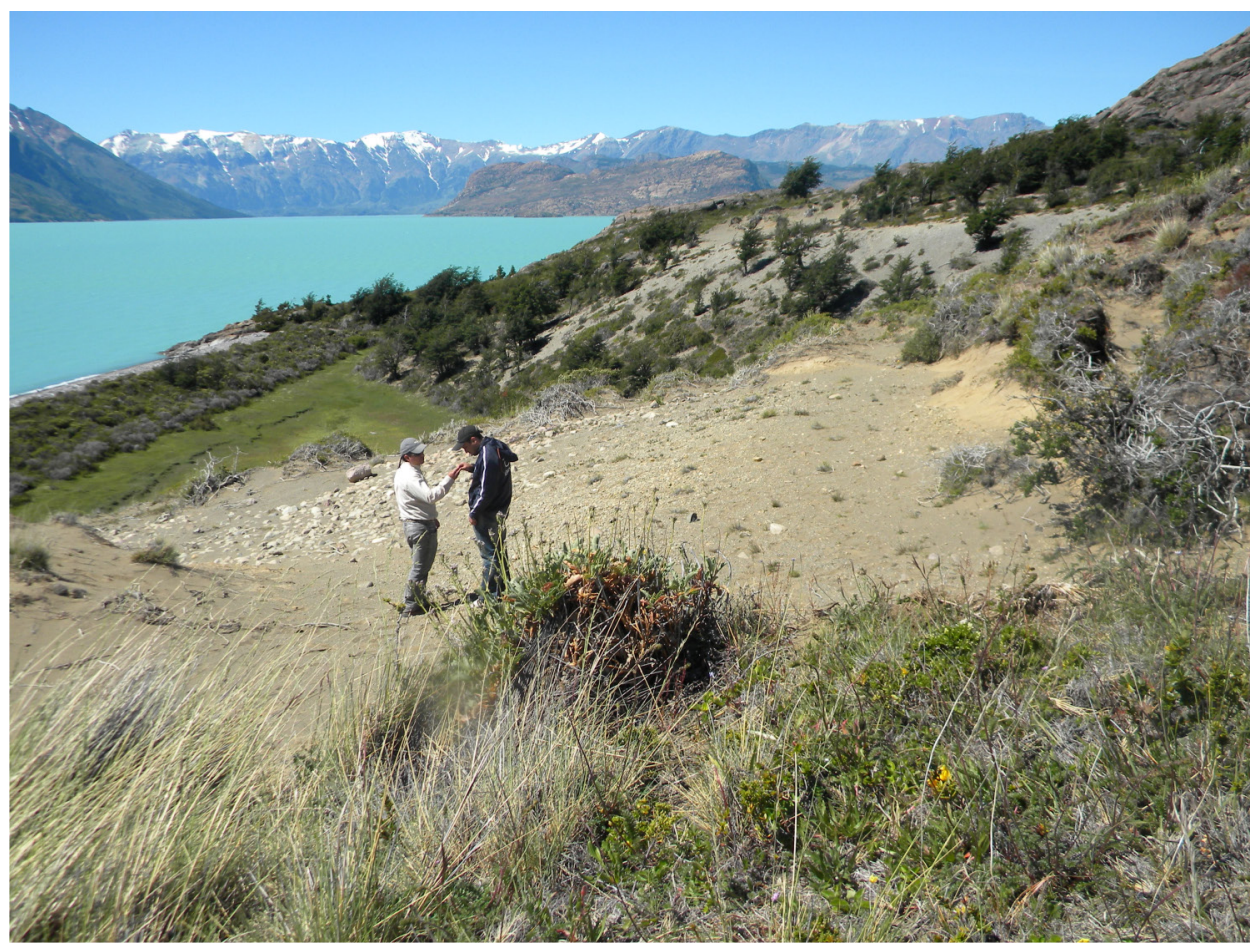

Figura 4. Puesto Martínez Rosas II.

\begin{tabular}{|l|l|l|l|l|l|l|l|}
\hline Tipo Artefactual & Obsidiana & Sílice & M. sil. & Basalto & Limolita & TSV & Total y \% \\
\hline L. secundaria & 1 & 0 & 0 & 0 & 0 & 0 & $1 / 3,44$ \\
\hline L. dorso natural & 4 & 0 & 0 & 0 & 0 & 0 & $4 / 13,79$ \\
\hline L. angular & 14 & 2 & 1 & 1 & 0 & 1 & $19 / 65,51$ \\
\hline L. arista & 0 & 0 & 0 & 0 & 1 & 0 & $1 / 3,44$ \\
\hline Chunk & 0 & 0 & 1 & 0 & 0 & 0 & $1 / 3,44$ \\
\hline Raspador & 2 & 0 & 0 & 0 & 0 & 0 & $2 / 6,83$ \\
\hline RBO & 1 & 0 & 0 & 0 & 0 & 0 & $1 / 3,44$ \\
\hline Total y \% & $22 /$ & $2 /$ & $2 /$ & $1 /$ & $1 /$ & $1 /$ & 29 \\
& 75,86 & 6,89 & 6,89 & 3,44 & 3,44 & 3,44 & \\
\hline
\end{tabular}

Tabla 11. Terraza lacustre. Puesto Martínez Rosas II (cuenca de deflación frente al puesto). Frecuencias de tipos artefactuales por materia prima. Referencias: L.: lasca; RBO: retoque en bisel oblicuo; M. sil.: madera silicificada; TSV: toba silicificada verde.

En el Puesto Martínez Rosas I los artefactos están confeccionados con rocas locales e inmediatamente disponibles, tales como las tobas, empleadas para la manufactura del $72,72 \%$ de los artefactos. Se recuperó un núcleo de madera silicificada agotado con extracciones multidireccionales. En esta roca se ha manufacturado un raspador y los restantes lo han sido en sílices. Así, se repite lo observado en las concentraciones anteriores con respecto al uso mayoritario de rocas locales.

Por su parte, en el Puesto Martínez Rosas II se privilegió el empleo de rocas alóctonas como la obsidiana ( $76 \%$ ) negra y atigrada para la manufactura de raspadores y un $\mathrm{RBO}$, los que han sido fabricados a partir de hemiguijarros con restos de corteza. Los primeros se 
encuentran enteros y con potencial de reactivación, mientras que el RBO está fracturado y presenta pátina. La otra materia prima no local es la limolita, presente en un desecho de talla $(3,44 \%)$. Lo señalado, permite no sólo diferenciar ambos espacios sino también proponer el trasporte de nódulos de obsidiana y su conservación como reaseguro, ya que su empleo se dio en el sector más oriental con evidencias de uso del interior del bosque. Cabe mencionar que las lascas externas de obsidiana $(n=5)$ muestran las mismas dimensiones que los nódulos que se pueden inferir a partir de los hemiguijarros.

Los sílices ocupan el tercer lugar en la representación porcentual con el 13,63\% de los artefactos, el resto de las rocas (madera silicificada, basalto y toba silicificada verde) están presentes en frecuencias muy bajas, entre el 9 y el 3\%. Para el caso del basalto, las dos lascas corresponden a dos nódulos diferentes. Algo semejante sucede con los 'silices ya que los cinco artefactos proceden de cuatro nódulos diferentes.

\section{Consideraciones generales}

En toda la muestra analizada las lascas internas $(79,16 \%)$ han sido seleccionadas como forma base para la confección de los artefactos formatizados, hay un único caso de una raedera en obsidiana manufacturada sobre un biface. Las raederas $(n=10)$ y los raspadores $(n=10)$ son las clases mayoritarias y han sido confeccionadas tanto sobre rocas disponibles localmente como alóctonas. La presencia de nódulos representados por una sola lasca en la mayoría de los conjuntos $(81,81 \%)$ apoya aún más la expeditividad de los mismos. Por otra parte, es concordante con la falta de planificación en el uso y el corto tiempo de permanencia en ese espacio.

Por último, se efectuó un relevamiento sumario del bosque de la laguna del Mosquito. En un sector denudado se registró una lasca angular de limolita $(100,5 \mathrm{~mm} \times 32 \mathrm{~mm}$ x 25 $\mathrm{mm}$ ). También se prospectó la margen Sur de la laguna y otras tres lagunitas localizadas inmediatamente hacia el Este; no se detectó material arqueológico.

\section{Dimensiones de los artefactos}

A continuación, para cada sector analizado se detalla la distribución porcentual de la longitud y el ancho de los desechos de talla (Tabla 12) y se contempla la distribución porcentual de los tipos de talón (Tabla 13). El mismo procedimiento se sigue con los artefactos formatizados (Tabla 14). Las variaciones en las frecuencias de las distintas tablas se relacionan con las posibilidades de medir cada dimensión ante la presencia de fracturas en diferentes sectores de los artefactos.

El $88,80 \%$ del conjunto de artefactos líticos $(\mathrm{N}=268)$ corresponde a desechos de talla que en su mayoría son internos $(83,61 \%)$. La distribución por intervalos de tamaños de los desechos indica que más del $90 \%(\mathrm{n}=108)$ son muy pequeños y pequeños (sensu Aschero 1975/1983), lo que es coincidente con los menores intervalos del ancho y el espesor. Con respecto a este último, su distribución porcentual en los desechos de talla muestra artefactos de hasta $15 \mathrm{~mm}$, siendo mayoritario el intervalo 5-9,9 $\mathrm{mm}$. La representación porcentual siguiente corresponde al tamaño mediano-pequeño, mostrando un neto predominio de los intervalos pequeño y mediano-pequeño en todo el conjunto. Con respecto a los tipos de talón de los desechos casi el 64\% no han sido preparados, lo que indica una baja inversión de energía (Tabla 13). Por su parte, la distribución de los artefactos formatizados por tamaños 


\begin{tabular}{|c|c|c|c|c|c|c|c|c|c|c|}
\hline \multirow[b]{2}{*}{$\begin{array}{l}\text { Intervalos } \\
(\mathrm{mm})\end{array}$} & \multicolumn{2}{|c|}{ Bloque El Cóndor } & \multicolumn{2}{|c|}{$\begin{array}{l}\text { Terraza del río } \\
\text { Grande (cuencas } \\
\text { de deflación } 2,3 \text { y } \\
\text { 4) }\end{array}$} & \multicolumn{2}{|c|}{$\begin{array}{l}\text { Terraza del río } \\
\text { Gallo (cuenca de } \\
\text { deflación 3) }\end{array}$} & \multicolumn{2}{|c|}{$\begin{array}{l}\text { Península } \\
\text { Mackenna } \\
\text { (cuencas de } \\
\text { deflación) }\end{array}$} & \multicolumn{2}{|c|}{$\begin{array}{l}\text { Puesto Martínez } \\
\text { Rosas I y II }\end{array}$} \\
\hline & $\begin{array}{l}\text { Largo } \\
(\mathrm{N}=108)\end{array}$ & $\begin{array}{l}\text { Ancho } \\
(\mathrm{N}=121)\end{array}$ & $\begin{array}{l}\text { Largo } \\
(\mathrm{N}=27)\end{array}$ & $\begin{array}{l}\text { Ancho } \\
(\mathrm{N}=30)\end{array}$ & $\begin{array}{l}\text { Largo } \\
(\mathrm{N}=3)\end{array}$ & $\begin{array}{l}\text { Ancho } \\
(\mathrm{N}=4)\end{array}$ & $\begin{array}{l}\text { Largo } \\
(\mathrm{N}=20)\end{array}$ & $\begin{array}{l}\text { Ancho } \\
(\mathrm{N}=19)\end{array}$ & $\begin{array}{l}\text { Largo } \\
(\mathrm{N}=29)\end{array}$ & $\begin{array}{l}\text { Ancho } \\
(\mathrm{N}=32)\end{array}$ \\
\hline $0-19,9$ & 70,37 & 62 & 22,22 & 23,33 & 0 & 0 & 0 & 0 & 17,24 & 31,25 \\
\hline $20-39,9$ & 27 & 33 & 37 & 50 & 66,33 & 50 & 55 & 58 & 38 & 50 \\
\hline $40-59,9$ & 3 & 3,30 & 33,33 & 20 & 0 & 0 & 25 & 21 & 31 & 12,5 \\
\hline $60-79,9$ & 0 & 2 & 7,40 & 7 & 33,33 & 25 & 10 & 16 & 10,34 & 3,12 \\
\hline $80-99,9$ & 0 & 0 & 0 & 0 & 0 & 25 & 5 & 5,26 & 3,44 & 3,12 \\
\hline $100-119,9$ & 0 & 0 & 0 & 0 & 0 & 0 & 2,5 & 0 & 0 & 0 \\
\hline $120-139,9$ & 0 & 0 & 0 & 0 & 0 & 0 & 0 & 0 & 0 & 0 \\
\hline $140-149,9$ & 0 & 0 & 0 & 0 & 0 & 0 & 2,5 & 0 & 0 & 0 \\
\hline
\end{tabular}

Tabla 12. Distribución porcentual de longitud y anchura de desechos de talla de acuerdo con los sectores analizados.

\begin{tabular}{|c|c|c|c|c|c|}
\hline & $\begin{array}{l}\text { Bloque El Cóndor } \\
(\mathrm{N}=134)\end{array}$ & $\begin{array}{l}\text { Terraza del río } \\
\text { Grande (cuencas } \\
\text { de deflación } 2,3 \text { y } \\
\text { 4) }(\mathrm{N}=31)\end{array}$ & $\begin{array}{l}\text { Terraza del río } \\
\text { Gallo (cuenca de } \\
\text { deflación } 3)(\mathrm{N}=4)\end{array}$ & $\begin{array}{l}\text { Península } \\
\text { Mackenna } \\
\text { (cuencas de } \\
\text { deflación) }(\mathrm{N}=21)\end{array}$ & $\begin{array}{l}\text { Puesto Martínez } \\
\text { Rosas I y II } \\
(\mathrm{N}=43)\end{array}$ \\
\hline Cortical & 0,74 & 15 & 25 & 25 & 6 \\
\hline Liso & 63 & 74 & 50 & 30 & 41,17 \\
\hline Facetado & 5,18 & 0 & 0 & 20 & 6 \\
\hline Puntiforme & 4,44 & 0 & 0 & 5 & 15 \\
\hline Filiforme & 24 & 11,11 & 25 & 20 & 20 \\
\hline Diedro & 2,22 & 0 & 0 & 0 & 12 \\
\hline
\end{tabular}

Tabla 13. Distribución porcentual del tipo de talón de los desechos de acuerdo con los sectores analizados.

\begin{tabular}{|c|c|c|c|c|c|c|c|c|}
\hline \multirow[b]{2}{*}{ Raspador } & \multicolumn{2}{|c|}{ Bloque El Cóndor } & \multicolumn{2}{|c|}{$\begin{array}{l}\text { Terraza del río } \\
\text { Grande (cuencas } \\
\text { de deflación } 2,3 \text { y } \\
\text { 4) }\end{array}$} & \multicolumn{2}{|c|}{$\begin{array}{l}\text { Península } \\
\text { Mackenna } \\
\text { (cuencas de } \\
\text { deflación) }\end{array}$} & \multicolumn{2}{|c|}{$\begin{array}{l}\text { Puesto Martínez } \\
\text { Rosas I y II }\end{array}$} \\
\hline & $\begin{array}{l}\text { Largo } \\
(\mathrm{N}=0)\end{array}$ & $\begin{array}{l}\text { Ancho } \\
(\mathrm{N}=0)\end{array}$ & $\begin{array}{l}\text { Largo } \\
(\mathrm{N}=2)\end{array}$ & $\begin{array}{l}\text { Ancho } \\
(\mathrm{N}=2)\end{array}$ & $\begin{array}{l}\text { Largo } \\
(\mathrm{N}=1)\end{array}$ & $\begin{array}{l}\text { Ancho } \\
(\mathrm{N}=1)\end{array}$ & $\begin{array}{l}\text { Largo } \\
(\mathrm{N}=6)\end{array}$ & $\begin{array}{l}\text { Ancho } \\
(\mathrm{N}=6)\end{array}$ \\
\hline $0-19,9^{*}$ & 0 & 0 & 0 & 0 & 0 & 0 & 16,67 & 16,67 \\
\hline $20-39,9$ & 0 & 0 & 50 & 100 & 0 & 100 & 50 & 66,66 \\
\hline $40-59,9$ & 0 & 0 & 50 & 0 & 0 & 0 & 33,33 & 16,67 \\
\hline $60-79,9$ & 0 & 0 & 0 & 0 & 100 & 0 & 0 & 0 \\
\hline Raedera & $\begin{array}{l}\text { Largo } \\
(\mathrm{N}=3)\end{array}$ & $\begin{array}{l}\text { Ancho } \\
(\mathrm{N}=4)\end{array}$ & $\begin{array}{l}\text { Largo } \\
(\mathrm{N}=0)\end{array}$ & $\begin{array}{l}\text { Ancho } \\
(\mathrm{N}=0)\end{array}$ & $\begin{array}{l}\text { Largo } \\
(\mathrm{N}=6)\end{array}$ & $\begin{array}{l}\text { Ancho } \\
(\mathrm{N}=6)\end{array}$ & $\begin{array}{l}\text { Largo } \\
(\mathrm{N}=0)\end{array}$ & $\begin{array}{l}\text { Ancho } \\
(\mathrm{N}=0)\end{array}$ \\
\hline $20-39,9$ & 33,33 & 25 & 0 & 0 & 0 & 0 & 0 & 0 \\
\hline $40-59,9$ & 33,33 & 75 & 0 & 0 & 16,67 & 83,33 & 0 & 0 \\
\hline $60-79,9$ & 33,33 & 0 & 0 & 0 & 83,33 & 16,67 & 0 & 0 \\
\hline Cepillo & $\begin{array}{l}\text { Largo } \\
(\mathrm{N}=0)\end{array}$ & $\begin{array}{l}\text { Ancho } \\
(\mathrm{N}=0)\end{array}$ & $\begin{array}{l}\text { Largo } \\
(\mathrm{N}=0)\end{array}$ & $\begin{array}{l}\text { Ancho } \\
(\mathrm{N}=0)\end{array}$ & $\begin{array}{l}\text { Largo } \\
(\mathrm{N}=2)\end{array}$ & $\begin{array}{l}\text { Ancho } \\
(\mathrm{N}=2)\end{array}$ & $\begin{array}{l}\text { Largo } \\
(\mathrm{N}=0)\end{array}$ & $\begin{array}{l}\text { Ancho } \\
(\mathrm{N}=0)\end{array}$ \\
\hline $40-59,9$ & 0 & 0 & 0 & 0 & 50 & 0 & 0 & 0 \\
\hline $80-99,9$ & 0 & 0 & 0 & 0 & 50 & 100 & 0 & 0 \\
\hline Cortante & $\begin{array}{l}\text { Largo } \\
(\mathrm{N}=0)\end{array}$ & $\begin{array}{l}\text { Ancho } \\
(\mathrm{N}=0)\end{array}$ & $\begin{array}{l}\text { Largo } \\
(\mathrm{N}=0)\end{array}$ & $\begin{array}{l}\text { Ancho } \\
(\mathrm{N}=0)\end{array}$ & $\begin{array}{l}\text { Largo } \\
(\mathrm{N}=2)\end{array}$ & $\begin{array}{l}\text { Ancho } \\
(\mathrm{N}=2)\end{array}$ & $\begin{array}{l}\text { Largo } \\
(\mathrm{N}=0)\end{array}$ & $\begin{array}{l}\text { Ancho } \\
(\mathrm{N}=0)\end{array}$ \\
\hline $20-39,9$ & 0 & 0 & 0 & 0 & 0 & 50 & 0 & 0 \\
\hline $80-99,9$ & 0 & 0 & 0 & 0 & 100 & 0 & 0 & 0 \\
\hline $120-139,9$ & 0 & 0 & 0 & 0 & 0 & 50 & 0 & 0 \\
\hline Biface & $\begin{array}{l}\text { Largo } \\
(\mathrm{N}=0)\end{array}$ & $\begin{array}{l}\text { Ancho } \\
(\mathrm{N}=0)\end{array}$ & $\begin{array}{l}\text { Largo } \\
(\mathrm{N}=1)\end{array}$ & $\begin{array}{l}\text { Ancho } \\
(\mathrm{N}=0)\end{array}$ & $\begin{array}{l}\text { Largo } \\
(\mathrm{N}=0)\end{array}$ & $\begin{array}{l}\text { Ancho } \\
(\mathrm{N}=0)\end{array}$ & $\begin{array}{l}\text { Largo } \\
(\mathrm{N}=0)\end{array}$ & $\begin{array}{l}\text { Ancho } \\
(\mathrm{N}=0)\end{array}$ \\
\hline $40-59,9$ & 0 & 0 & 100 & 0 & 0 & 0 & 0 & 0 \\
\hline $140-149,9$ & 0 & 0 & 0 & 0 & 50 & 0 & 0 & 0 \\
\hline $\mathrm{RBO}$ & $\begin{array}{l}\text { Largo } \\
(\mathrm{N}=0)\end{array}$ & $\begin{array}{l}\text { Ancho } \\
(\mathrm{N}=0)\end{array}$ & $\begin{array}{l}\text { Largo } \\
(\mathrm{N}=0)\end{array}$ & $\begin{array}{l}\text { Ancho } \\
(\mathrm{N}=0)\end{array}$ & $\begin{array}{l}\text { Largo } \\
(\mathrm{N}=0)\end{array}$ & $\begin{array}{l}\text { Ancho } \\
(\mathrm{N}=0)\end{array}$ & $\begin{array}{l}\text { Largo } \\
(\mathrm{N}=0)\end{array}$ & $\begin{array}{l}\text { Ancho } \\
(\mathrm{N}=1)\end{array}$ \\
\hline $20-39,9$ & 0 & 0 & 0 & 0 & 0 & 0 & 0 & 100 \\
\hline
\end{tabular}

Tabla 14. Distribución porcentual de longitud y anchura de los artefactos formatizados de acuerdo con los sectores analizados. Referencias: *Intervalos en mm. RBO: retoque en bisel oblicuo. 
(Tabla 14) es dominada por los pequeños y mediano-pequeños, mientras que los espesores se ubican entre 5 y 29,9 $\mathrm{mm}$. La excepción es uno de los cepillos que alcanza los $40 \mathrm{~mm}$. Los artefactos formatizados de mayores dimensiones corresponden a los cepillos y las raederas, confeccionadas sobre rocas de disponibilidad local.

\section{Discusión y conclusiones}

La información paleoambiental indica que el registro arqueológico aquí presentado siempre habría estado en el interior del bosque de la margen Sur del lago San Martín. Dicho registro tiene una distribución puntual y relativamente continua, conformada por eventos de talla de baja densidad y riqueza artefactual localizados sobre las terrazas de los ríos Cóndor, Grande y Gallo, la morena de la península Mackenna y la terraza lacustre donde se encuentra el Puesto Martínez Rosas. Si bien esto puede ser producto del muestreo, focalizado sobre aquellos espacios con buena visibilidad arqueológica, el hecho de que no todos ellos presenten evidencias arqueológicas ya sugiere una baja intensidad de uso del interior del bosque. Los resultados señalan la utilización de este espacio, pero sin modificar el patrón de baja intensidad registrado anteriormente (Espinosa et al. 2009, 2013). Al respecto, restaría evaluar si la distribución artefactual continúa del lado chileno (lago O’Higgins). Los conjuntos se componen mayoritariamente por desechos de talla de tamaños pequeños y muy pequeños, con talones no preparados. La frecuencia de artefactos formatizados también es baja, los porcentajes más altos corresponden a raederas y raspadores. Es destacable la baja frecuencia de bifacialidad - sólo una raedera y un biface- en superficie y nueve lascas de reducción bifacial en la estratigrafía del Bloque El Cóndor, aunque es posible que no se hayan interceptado los lugares de descarte de otros artefactos bifaciales tales como puntas de proyectil. Así y todo, la señal arqueológica es muy tenue.

El empleo mayoritario de rocas disponibles localmente -aunque sus tipos y frecuencias son diferentes- y la alta frecuencia de lascas que se corresponden con un solo nódulo (Larson y Kornfeld 1997) indica el aprovechamiento inmediato de materia prima, sin mediar transporte hacia lugares de mayor permanencia. Esto muestra un importante componente expeditivo de la tecnología. Además, no hay evidencias que permitan defender el equipamiento de espacios; por el contrario es posible proponer ocupaciones no persistentes en el tiempo. En igual sentido se inclina la información estratigráfica obtenida en el Bloque El Cóndor, donde la intensidad de uso decrece a partir de los momentos iniciales.

Otra señal acerca de la baja intensidad de uso está dada por las escasas evidencias de empleo de la toba silicificada verde. Hacia el Oeste del istmo de la península Maipú su presencia ya no es preponderante, la frecuencia decae abruptamente a partir del Bloque El Cóndor, luego hay sólo dos lascas angulares en el río Gallo y una en el Puesto Martínez Rosas II. Si bien esta roca se encuentra en el camino obligado al interior del bosque continuando por el brazo Maipú, los cazadores prácticamente no se aprovisionaron de esta materia prima de muy buena calidad para la talla. Si hubiera estado previsto el uso/circulación más intenso y/o recurrente del interior del bosque, sería esperable que una roca con estas propiedades se encontrara más representada y que exhibiera una curva de decaimiento menos pronunciada.

En líneas generales, la variabilidad artefactual es la misma que en la estepa, situación ya descripta para otras regiones del bosque cordillerano patagónico (Bellelli et al. 2000; Belardi y Campan 1999; Borrero y Muñoz 1999; Espinosa 2000, 2002, entre otros). Además, en ambos ecosistemas se emplearon mayoritariamente los mismos tipos de rocas: silíceas, tobas, 
basalto, obsidiana y limolita. Como se mencionara, la presencia de artefactos de obsidiana, limolita y toba silicificada verde indican su ingreso desde el Este por parte de individuos equipados con estas rocas (Kuhn 1995). La bola encontrada en las inmediaciones del Bloque El Cóndor reforzaría esta idea dada su asociación con espacios abiertos. Los artefactos recuperados en el Puesto Martínez Rosas muestran el uso de la obsidiana para la manufactura de instrumentos de filos cortos restringidos (raspadores y un RBO). El hecho de que hayan sido confeccionados sobre hemiguijarros con restos de corteza sustenta el transporte de nódulos enteros, como se registrara en la margen Este del lago Tar y los alrededores del cerro Cach Aike, aunque en estos casos son de mayores tamaños. Es llamativo que sea el sector más oriental el que muestre la mayor frecuencia de artefactos de obsidiana. Esto podría relacionarse con el transporte de nódulos en un marco donde se buscaría asegurar la disponibilidad de rocas óptimas para la talla. Además, implicaría el conocimiento que más hacia el Oeste de este punto es muy difícil circular dadas las características topográficas del sector chileno y la presencia del CHPS.

La distribución puntual de las concentraciones líticas, sus bajas densidades y riquezas, el empleo mayoritario y expeditivo de rocas disponibles localmente -avalado por la alta diversidad de nódulos con muy baja representación artefactual-, el uso acotado de la toba silicificada verde y el diferido de la obsidiana, sumado a la marcada estacionalidad, sugieren que el espacio ubicado hacia el Oeste de la península Maipú fue circulado de manera ocasional por caminos de menor costo y por corto tiempo, mostrando una muy baja intensidad de uso por parte de poblaciones procedentes del Este. Esta señal se vincularía con una extensión de los radios logísticos con fines exploratorios. A la vez, difiere de la registrada en la margen Norte del lago San Martín e indicaría el aprovechamiento de oportunidades de exploración aún cuando no haya recursos distintos a los que se pueden obtener sin mediar mayores desplazamientos.

La nueva evidencia es consistente con la propuesta de que el uso del bosque austral sólo puede ser entendido en relación con la estepa (Belardi y Campan 1999; Borrero y Muñoz 1999; Espinosa 2000, 2002; Méndez y Reyes 2008, entre otros). Si bien se carece de cronología, ello se habría dado con mayor énfasis durante el Holoceno tardío. Estas particularidades, junto con el uso marginal del bosque en la cuenca del lago San Martín, se ajustan a lo registrado en otras regiones del sur de Santa Cruz: las cuencas de los lagos Argentino y Viedma, las nacientes del río Gallegos y, si bien con una mayor intensidad de uso, en el Parque Nacional Perito Moreno.

Si se compara la información del uso humano del bosque en Santa Cruz con la del norte de Patagonia (provincias de Río Negro y Chubut) se plantean marcadas diferencias (ver Borrero 1994-1995). En primer lugar, se debe establecer la existencia de variaciones ecológicas vinculadas con gradientes latitudinales y de precipitación (Veblen et al. 2002). La primera de ellas se relaciona con la presencia del CHPS y una estacionalidad más marcada, ya que no es posible atravesar esta barrera sino hacia el extremo austral, mientras que en Patagonia Norte son frecuentes las evidencias de circulación entre las márgenes continentales (Bellelli et al. 2008).

En Patagonia Norte se ha propuesto que las poblaciones cazadoras recolectoras emplearon este ambiente en forma permanente o semipermanente, aunque lo complementaron con recursos provenientes de la estepa o el ecotono (Bellelli et al. 2000; Carballido y Fernández 2013; Fernández et al. 2011, entre otros). Por otra parte, el desarrollo de una tecnología de 
navegación habría favorecido el desplazamiento dentro del bosque (Hajduk et al. 2004, entre otros). A la vez, los sitios tienen evidencias de reocupaciones a lo largo del tiempo y con una señal más clara durante el tramo final del Holoceno, mientras que en los de Patagonia Sur sólo es posible defender ocupaciones poco densas y no reiteradas. Además, en Patagonia Norte existe una alta frecuencia de sitios con manifestaciones rupestres con cronologías del Holoceno tardío, algunos de ellos con alta densidad de motivos (Bellelli et al. 2008; Fernández et al. 2011). En el Sur estos tipos de sitios son menos frecuentes, como así también lo es la densidad de motivos rupestres. A ello debe sumarse la existencia de un patrón de enterratorios humanos bien diferenciado en Patagonia Norte (Rizzo 2013). Estos contrastes podrían obedecer, entre otras causas, a diferencias en la capacidad de sustento del bosque, a las mayores posibilidades de circulación y a una más alta demografía humana en Patagonia Norte. Si bien con menos evidencias que en la estepa, la discusión es igual de intensa.

Agradecimientos: A Roberto Andreone, Silvana Espinosa, Alejandro Súnico, Gustavo Barrientos y Daniel Grima por su colaboración. A Florencia Bamonte, Mariana Carballido Calatayud, Luis Borrero y a los dos evaluadores anónimos por la lectura crítica del manuscrito. A Pedro Tiberi por la confección de los mapas. A Alejandro Serret y Jaime Smart, al personal de la Ea. El Cóndor y a Cielos Patagónicos por su inestimable apoyo en el campo. A Javier Infante y a la Dirección Provincial de Vialidad. El trabajo se realiza en el marco de los proyectos UNPA 29/A304 y CONICET PIP 0418.

\section{Bibliografía citada}

Andreone, R.

2011 Estudio de impacto ambiental ampliación de la ruta provincial No 41. Tramo 2. Informe presentado a la Dirección provincial de Vialidad.

Aragón, E. y N. V. Franco

1997 Características de rocas para la talla por percusión y propiedades petrográficas. Anales del Instituto de la Patagonia 25: 187-199.

Aschero, C.

1975 rev. 1983 Ensayo para una clasificación morfológica de los instrumentos líticos aplicada a estudios tipológicos comparativos. Informe al CONICET.

1996 ¿Adonde van esos guanacos? Arqueología. Sólo Patagonia (ed. por J. Gómez Otero), pp. 153-162. CENPAT-CONICET. Puerto Madryn.

Aschero, C., R. A. Goñi, M. T. Civalero, R. Molinari, S. L. Espinosa, G. Guraieb y C. Bellelli 2005 Holocenic Park: arqueología del Parque Nacional Perito Moreno. Anales de Parques Nacionales XVII: 71-119.

Aüer, V. y D. Cappannini

1957 La erosión en la región de los lagos San Martín y Tar. IDIA (Marzo): 7-27.

Bamonte, F.

2012 Cambios paleoecológicos y su posible relación con las ocupaciones humanas durante el Holoceno en el SO de Santa Cruz, Argentina. Tesis doctoral. Universidad Nacional de Mar del Plata. 
Bamonte, F. P. y M. V. Mancini

2011 Palaeoenvironmental changes since Pleistocene-Holocene transition: pollen analysis from a wetland in Southwestern Patagonia (Argentina). Review of Paleobotany and Palynology 165 (1-2): 103-110.

Belardi, J. B. y P. Campán

1999 Estepa y Bosque: La utilización de lagos y lagunas en la región de lago Argentino, provincia de Santa Cruz. Soplando en el viento. Actas III Jornadas de Arqueología de la Patagonia, pp: 25-41. Instituto Nacional de Antropología y Pensamiento Latinoamericano y Universidad Nacional del Comahue. San Carlos de Bariloche.

Belardi, J. B y S. Caracotche

2005 Resultados arqueológicos en el noroeste del lago Viedma, Provincia de Santa Cruz. Actas del XIII Congreso Nacional de Arqueología. Tomo 4: 81-88. Córdoba.

Belardi, J. B., F. Carballo Marina, M. I. Hernández Llosas y H. Cepeda 1994 Arqueología del bosque: el área del lago Roca (Lago Argentino, Provincia de Santa Cruz). Actas y Memorias (Segunda Parte). XI Congreso Nacional de Arqueología Argentina. Revista del Museo de Historia Natural de San Rafael XIV (1-4): 282-284.

Belardi, J. B., G. Cassiodoro, R. Goñi, M. Glascock y A. Súnico

2013 Limolites from Southern Patagonia (Argentina): their source and archaeological artifact distributions. Abstracts 78th Annual Meeting. Publicación digital. Society for American Archaeology, Honolulu.

Belardi, J. B., S. Espinosa, F. Carballo Marina, G. Barrientos, R. A. Goñi, A. Súnico, T. Bourlot, C. Pallo, A. Tessone, S. García Guraieb, A. Re y P. Campan

2010 Las cuencas de los lagos Tar y San Martín (Santa Cruz, Argentina) y la dinámica del poblamiento humano del sur de Patagonia: integración de los primeros resultados. Magallania 38 (2): 137-159.

Bellelli, C., V. Scheinsohn, P. Fernández, F. Pereyra, M. Podestá y M. Carballido 2000. Arqueología de la Comarca Andina del Paralelo 42․ Localidad de Cholila. Primeros resultados. Desde el país de los Gigantes. Perspectivas arqueológicas de Patagonia. Editado por la Universidad Nacional de la Patagonia Austral, pp: 587-602. Río Gallegos, Santa Cruz

Bellelli, C., V. Scheinsohn y M. M. Podestá

2008 Arqueología de pasos cordilleranos: un caso de estudio en Patagonia norte durante el Holoceno tardío. Boletín del Museo Chileno de Arte Precolombino 13(2): 37-55.

Bonarelli, G. y J J. Nagera

1921 Observaciones geológicas en las inmediaciones del lago San Martín (Territorio de Santa Cruz). Boletín Ministerio de Agricultura. Dirección General de Minas, Geología e Hidrología Serie B (Geología) No 27.

Borrero, L. A.

1994-1995 Arqueología de la Patagonia. Palimpsesto. Revista de Arqueología 4: 9-69.

2004 The Archaeozoology of Andean "Dead Ends" in Patagonia: Living near the Continental Ice Cap. Colonisation, Migration and Marginal Areas. A zooarchaeological approach (ed. por M.Mondini, A. S. Nuñoz y S. Wickler), pp 55-61. OxbowBooks, Oakville. 
Borrero, L. A. y A. S. Muñoz

1999. Tafonomía en el bosque patagónico. Implicaciones para el estudio de su explotación y uso por poblaciones humanas de cazadores-recolectores. Soplando en el viento. Actas de las III Jornadas de Arqueología de la Patagonia, pp: 43-56. Instituto Nacional de Antropología y Pensamiento Latinoamericano y Universidad Nacional del Comahue. San Carlos de Bariloche.

Carballido Calatayud, M. y P. Fernández

2013 La caza de ungulados en el bosque de Patagonia. Aportes desde la localidad de Cholila (Chubut, Argentina).Relaciones de la Sociedad Argentina de Antropología 38 (1): 59-82.

Charlín, J. L. A. Borreroy M. C. Pallo

2011 Ocupaciones humanas en el área noroccidental del río Gallegos (prov. de Santa Cruz, Argentina). Bosques, Montañas y Cazadores: Investigaciones arqueológicas en Patagonia Meridional (comp. por L. Borrero y K. Borrazo), pp:179-210. CONICET-IMHICIHU. Editorial Dunken.

Espinosa, S. L.

2000 Los conjuntos artefactuales líticos de la estepa y el bosque en el Parque Nacional Perito Moreno (Santa Cruz, Argentina). Desde el País de los Gigantes. Perspectivas arqueológicas en Patagonia, Tomo II: 357-367. Universidad Nacional de la Patagonia Austral, Río Gallegos.

2002 Estrategias tecnológicas líticas y uso del espacio en momentos tardíos en el Parque Nacional Perito Moreno (Santa Cruz). Tesis doctoral. Facultad de Filosofía y Letras. Universidad de Buenos Aires.

Espinosa, S. L. y R. Goñi

1999 Viven!! Una fuente de obsidiana en la provincia de Santa Cruz. Soplando en el viento. Actas de las III Jornadas de Arqueología de la Patagonia, pp: 177-188. Instituto Nacional de Antropología y Pensamiento Latinoamericano y Universidad Nacional del Comahue. San Carlos de Bariloche.

Espinosa, S. L., J. B. Belardi, G. Barrientos y F. Carballo Marina 2013 Poblamiento e intensidad de uso del espacio en la cuenca del lago San Martin (Patagonia argentina): nuevos datos desde la margen norte. Comechingonia 17 (1):105-121.

Espinosa, S. L., J. B. Belardi y A. Súnico

2009 ¿Cuán al oeste? Arqueología del istmo de la península Maipú (lago San Martín, provincia de Santa Cruz) en su contexto regional. Arqueología 15: 187-205.

Fernández, P., M. Carballido Calatayud, C. Bellelli, M. Podestá y V. Scheinsohn 2011 Marcas en la piedra, huellas en la tierra. El poblamiento del bosque del suroeste de Río Negro- noroeste de Chubut. Procesos históricos, transformaciones sociales y construcciones de fronteras. Aproximaciones a las relaciones interétnicas (Estudios sobre Norpatagonia, Argentina y Labrador, Canadá) (ed. por S. Valverde, G. Maragliano, M. Impemba y F. Trentini), pp. 195-221. Facultad de Filosofía y Letras, Universidad de Buenos Aires.

Franco, N. V.

2002 Estrategias de utilización de recursos líticos en la cuenca superior del río Santa Cruz. Tesis doctoral. Facultad de Filosofía y Letras, Universidad de Buenos Aires. 
Franco, N.V., P. Ambrústolo, F. Skarbun, N. Cirigliano y M. Martucci

2011 El Macizo del Deseado como fuente de aprovisionamiento de rocas silíceas. Variaciones en disponibilidad y circulación: Algunos ejemplos. Cazadores-recolectores del Cono Sur. Revista de Arqueología. 5: 81-95.

Franco, N. V., L. A. Borrero, J. B. Belardi, F. Carballo Marina, F. Martin, P. Campan, C. Favier Dubois, M. I. Hernández Llosas, N. Stadler, S. Muñoz, F. Borella, H. Cepeda e I. Cruz 1999 Arqueología del cordón Baguales y sistema lacustre al sur del lago Argentino. Praehistoria 3: 65-86.

Gilli, A., F. Anselmeti, D. Ariztegui, J. Bradbury, K, Kelts, V. Markgraf y J. McKenzie 2001 Tracking abrupt climate change in the Southern Hemisphere: a seismic stratigraphic study of Lago Cardiel, Argentina (49 ${ }^{\circ}$ ). Terra Nova 13 (6): 443-448.

Hajduk, A., A. Albornoz y M. Lezcano

2004 El Mylodon en el patio de atrás. Informe preliminar sobre los trabajos en el sitio El Trébol, ejido urbano de San Carlos de Bariloche, provincia de Río Negro. Contra viento y marea. Arqueología de Patagonia (ed. por T. Civalero, P. Fernández y G. Guraieb), pp. 715-732. Instituto Nacional de Antropología y Pensamiento Latinoamericano.

Kastner, S., D. Enters, C. Ohlendorf, T. Haberzettl, G. Kuhn, A. Lücke, C. Mayr, Jean-Louis Reyss, S. Wastegard y B. Zolitschka

2010 Reconstructing 2000 years of hydrological variation derived from laminated proglacial sediments of Lago del Desierto at the eastern margin of the South Patagonian Ice Field, Argentina. Global and Planetary Change 72: 201-214.

Kuhn, S. L.

1995 Mousterian Lithic Technology. An Ecological Perspective. Princeton University Press, Princeton.

Larson, M. L. y M. Kornfeld

1997 Chipped stone nodules: theory, method, and examples. Lithic Technology 22 (1): 4-18.

Masiokas, M. H., B. H. Luckman, R. Villalba, S. Delgado, P. Skvarka y A. Ripalta 2009 Little Ice Age fluctuations of small glaciers in the Monte Fitz Roy and Lago del Desierto areas, south Patagonian Andes, Argentina. Palaeogeography, Palaeoclimatology, Palaeoecology 281: 351-362.

Méndez C., R. Barberena, O. Reyes y A. Nuevo Delaunay

2013 Isotopic Ecology and Human Diets in the Forest-Steppe Ecotone, Aisén Region, CentralWestern Patagonia, Chile. International Journal of Osteoarchaeology. Published online in Wiley Online Library DOI: 10.1002/oa.2337.

Méndez, C. y O. R. Reyes

2008 Late Holocene human occupation of the Patagonian forests: a case study in the Cisnes river basin. Antiquity 82 (317): 560-570.

Movia, C., A. Soriano y R. León

1987 La vegetación de la cuenca del río Santa Cruz (Provincia de Santa Cruz, Argentina). Darwiniana 28: 9-70. 
Nami, H. G.

1986 Experimentos para el estudio de la tecnología bifacial de las ocupaciones tardías en el extremo sur de la Patagonia continental. Informes de Investigación 5. Programa de Estudios Prehistóricos.

Peri, P. y S. Ormaechea

2013 Relevamiento de los bosques nativos de ñire (Nothofagus antarctica) en Santa Cruz: base para su conservación y manejo. Ministerio de Agricultura, Ganadería y Pesca. Presidencia de la Nación. INTA. Ediciones Instituto Nacional de Tecnología Agropecuaria.

Rizzo, F.

2013 Registro funerario, uso del espacio y movilidad en el noroeste de Patagonia (provincias de Río Negro y Chubut). Primeros resultados. Relaciones de la Sociedad Argentina de Antropología 38 (1): 137-168.

Sottile, G. D., F. P. Bamonte, M. V. Mancini y M. M. Bianchi

2012 Insights into Holocene vegetation and climate changes at the Southeastern side of the Andes: Nothofagus Forest and Patagonian Steppe fire records. The Holocene 22 (1): 309-322.

Surface-Evans, S. L. y D. A. White.

2012 An Introduction to the least Cost Analysis of Social Landscapes. Least Cost Analysis and Social Landscapes. Archaeological Case Studies (ed. por D. A. White y S. L. Surface-Evans), pp. 1-7. The University of Utah Press, Salt Lake City.

Veblen, T., T Kitzberger y R.Villalba

2002 Nuevos paradigmas en ecología y su influencia sobre el conocimiento de la dinámica de los bosques del sur de Argentina y Chile. Ecología y manejo de los bosques de Argentina (ed. por Arturi, M. F.; J. L. Frangi y J. F. Goya), pp: 1-48. Editorial de la Universidad Nacional de La Plata.

Wenzens, G.

1999 Fluctuations of Outlet and Valley Glaciers in the Southern Andes (Argentina) during the Past 13,000 Years. Quaternary Research 51: 238-247. 